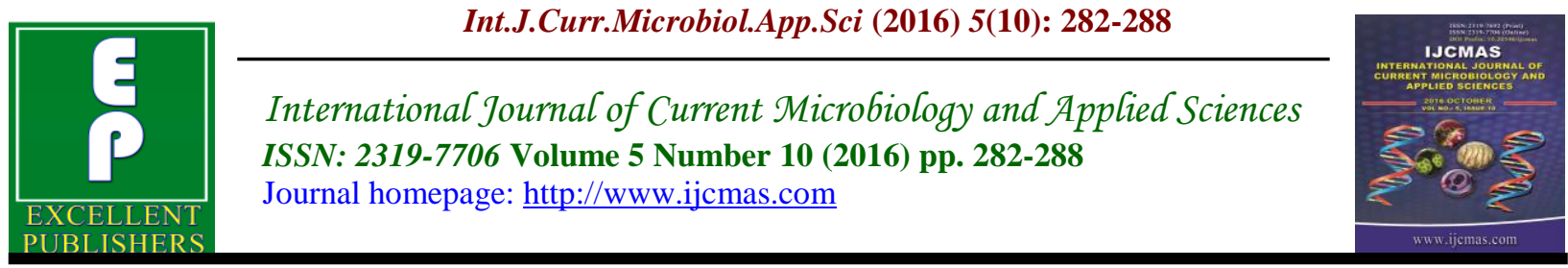

Original Research Article http://dx.doi.org/10.20546/ijcmas.2016.510.031

\title{
Bacterial Study of CSOM and their Changing Patterns of Antibiotic Sensitivity and Resistance
}

\author{
Upasana Bhumbla $^{1}$, Shobha Paul ${ }^{2}$, Dinesh Raj Mathur ${ }^{3}$ and Gyaneshwari ${ }^{3}$ \\ ${ }^{1}$ AIIMS Campus, Rishikesh-249203, India \\ ${ }^{2}$ Department of Microbiology, MNR Medical College, Sangareddy, India \\ ${ }^{3}$ Department of Microbiology, Shadan Institute of Medical Sciences, Hyderabad, India \\ *Corresponding author
}

Keywords

Chronic

Suppurative Otitis

Media (CSOM),

MRSA,

ESBL.

\section{Article Info}

Accepted:

14 September 2016 Available Online:

10 October 2016

\section{A B S T R A C T}

Chronic Suppurative Otitis Media is the most common childhood infectious disease worldwide. It is the most common cause of hearing impairment in the developing world, although it is infrequently seen in the developed world. It is an inflammatory condition of the ear that causes recurrent ear discharge or otorrhoea, through a perforation of the ear drum or tympanic membrane. It is also found to be the single major cause for conductive deafness, and is responsible for $1.5 \%$ speech disorders. To study the spectrum of bacterial etiological agents among patients clinically diagnosed as CSOM. This study was conducted on 105 patients of clinically diagnosed cases of CSOM attending ENT OPD. After proper sample collection by sterile aural swabs, they were immediately sent to the microbiology laboratory for aerobic bacterial culture, isolation and identification. Routine antibacterial susceptibility and detection of MRSA and ESBL was carried as per CLSI guidelines. The commonest age group affected was 10 months-10 years (28.5\%) mainly affecting males (60\%).Patients were mainly from rural background (81.91\%) and majority of cases were reported in the months of July to September(45.7\%). Out of 105 patients, Gram negative isolates were 51 (48.5\%) and Gram positive isolates were $32(30.4 \%)$ and remaining 17 (16.1\%) showed no growth. P. aeruginosa (34.3\%) was the predominant bacterial organism isolated, followed by Staphylococcus aureus (28.6\%). Out of 28 isolates of S. aureus, 10 (35.7\%) were MRSA and out of 18 Gram negative isolates, 5 (27.7\%) were ESBL producers. Antibiogram of isolates revealed that Amikacin was the most sensitive drug amongst all gram positive and gram negative organisms. Imipenem was the most sensitive drug among gram negative isolates whereas Vancomycin was the most sensitive drug among gram positive isolates.

\section{Introduction}

Chronic serous Otitis Media is not the same as Chronic Suppurative Otitis Media. The former may be defined as a middle ear effusion, without perforation, persisting for more than 1-3 months (Charles, 2006). Chronic Suppurative Otitis Media is characterized by drainage from the middle ear for at least two weeks and is associated 
with a tympanic membrane perforation that is usually painless (Dhingra, 2004; Miles et al., 2007).

The disease typically occurs in the young child and generally results from an acute ear infection that is not diagnosed promptly or is inadequately treated. It may also be a sequel of less severe forms of otitis media (otitis media with effusion). Experts dispute the duration of otorrhoea required to determine it as a chronic infection - the World Health Organization's definitions suggest more than two weeks; others contend longer (eg up to six weeks). It is also found to be the single major cause for conductive deafness, and is responsible for $1.5 \%$ speech disorders. Hearing loss associated with CSOM hampers educational skills in children that are well recognized by otologists, paediatricians and educators.

With the advent of antibiotics, the availability of newer technology and a growing awareness regarding the disease, the incidence of complications is decreased from $2.3 \%$ to $0.04 \%$. But, irrational use of antibiotics has led to the emergence of organisms resistant to the commonly used drugs. Therefore, the study of microorganisms commonly associated with CSOM and their antibiotic sensitivity pattern is vital for the clinician to plan a general outline of treatment for the patient with a chronically discharging ear.

The main of this study includes, investigating bacterial etiological agents amongst patients which are clinically diagnosed as Chronic Suppurative Otitis Media in ENT Outpatient department of a tertiary care hospital of South India. Identifying the organism isolated, using a battery of biochemical reactions.

To study the pattern of antibiotic sensitivity of isolates with reference to Methicillin resistant Staphylococcus aureus (MRSA) and Extended Spectrum of beta lactamases (ESBLs).

\section{Materials and Methods}

The study was conducted for a period of one year on 105 patients of all the clinically diagnosed cases of CSOM to the ENT outpatient department in a tertiary care hospital of South India. Ethical clearance was taken and informed consent from the patient/ guardian was also taken.

Ear discharge was collected under aseptic precautions in clinically diagnosed cases of CSOM attending ENT outpatient department.

After all sterile measures, two aural swabs were collected. Both the swabs were processed immediately in the laboratory for aerobic bacterial culture on 5\% sheep blood agar, Mac conkey agar and chocolate agar and than kept for incubation at $37^{\circ} \mathrm{C}$ for 48 hours. Second aural swab was used for direct microscopy. Isolation and identification of the organisms were done as per standard laboartory standards.

Routine antimicrobial susceptibility was done on Muller Hinton agar and detection of MRSA and ESBL was carried as per CLSI guidelines. For MRSA detection, disc pottentiation was done and for ESBL detection, disc potentiation and double disc diffusion tests were done (Forber et al., 1998; Washington et al., 2006).

\section{Results and Discussion}

Ear swabs were collected from 105 clincally diagnosed patients of CSOM out of which $63(60 \%)$ were males and 42(40\%) were females. The predominant age group ranged from 10 months- 10 years. $(28.5 \%)$. 
Maximum number of cases were mainly from rural areas $81.91 \%$ as compared to urban $18.09 \%$, where the peak season of
CSOM was observed in the month of JulySeptember $(48 / 45.71 \%)$ as shown in the graph.

Graph showing seasonal trend of CSOM patients

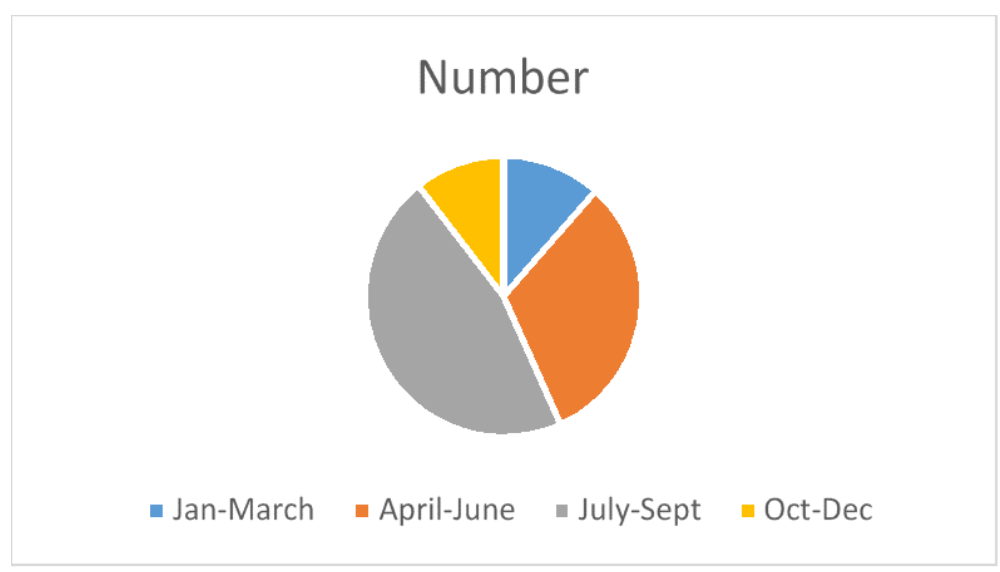

Out of 105 patients, 88 were positive for aerobic bacteria culture and remaining 17 were with no growth. Out of these 88 isolates, 83 were monobacterial and 5 were with polybacterial growth. Out of these 83 isolates, Pseudomonas aeruginosa was the most predominant organism 33(31.4\%) and Staphylococcus aureus 28(26.7\%) being the second most common organism as shown in Table-1

\begin{tabular}{|l|c|}
\hline Organisms & Total no.of cases \\
\hline P.aeruginosa & 33 \\
\hline S.aureus & 28 \\
\hline P.mirablis & 09 \\
\hline K.pneumoniae & 07 \\
\hline S.pyogenes & 04 \\
\hline Acinetobacterspp & 02 \\
\hline Mixed growth & 05 \\
\hline No growth & 17 \\
\hline
\end{tabular}

Antibiotic susceptibility pattern of these 88 isolates showed that Amikacin was the most sensitive drug amongst all the bacterial isolates whereas Vancomycin showed maximum susceptibility to Gram positive isolates. Imipenem showed maximum susceptibility to Gram negative isolates including Pseudomonas aeruginosa.

Out of 28 Staphylococcus aureus isolated, $10(35.7 \%)$ were MRSA producers and out of 18 Gram negative isolates, $5(27.7 \%)$ were ESBL producers. 


\begin{tabular}{|c|c|c|c|}
\hline Antibiotics & $\begin{array}{c}\text { Gram positive } \\
\text { isolates n=32 }\end{array}$ & $\begin{array}{c}\text { Gram Negative } \\
\text { isolates n=18 }\end{array}$ & $\begin{array}{c}\text { P.aeruginosa } \\
\text { isolates n=33 }\end{array}$ \\
\hline Vancomycin (VA) & $100 \%$ & - & - \\
\hline Clindamycin (CD) & $21.8 \%$ & - & - \\
\hline Linezolid (LZ) & $76.5 \%$ & - & - \\
\hline Erythromycin (E) & $53.1 \%$ & - & - \\
\hline Ampicillin (AMP) & $59.3 \%$ & - & - \\
\hline Amoxyclav (AMC) & $50 \%$ & - & $69.6 \%$ \\
\hline Ceftriaxone (CTR) & $73.5 \%$ & $55.6 \%$ & - \\
\hline Cefoxitin (CX) & $68.7 \%$ & - & $61.1 \%$ \\
\hline Cefotaxime (CTX) & - & $44.4 \%$ & $27.3 \%$ \\
\hline Ceftazidime (CAZ) & - & $38.9 \%$ & $66.7 \%$ \\
\hline Gentamicin (GEN) & $37.4 \%$ & $38.9 \%$ & $86.1 \%$ \\
\hline Amikacin (AK) & $81.2 \%$ & $72.2 \%$ & $63.6 \%$ \\
\hline Imipenem (IPM) & - & $94.4 \%$ & - \\
\hline Piperacillin + & - & $66.7 \%$ & $30.4 \%$ \\
\hline Tazobactum (TZP) & & & $39.4 \%$ \\
\hline Cefopodoxime (CPZ) & - & $33.3 \%$ & - \\
\hline Ciprofloxacin (CIP) & - & - & - \\
\hline Netlimicin (NET) & - & $27.7 \%$ & \\
\hline MRSA & $35.7 \%$ & & - \\
\hline ESBL producers & - & & \\
\hline
\end{tabular}

Maximum cases of CSOM were seen between the age group of 10 months-10years (28.5\%) this finding corroborates with the observations made by other researchers (Mohammed et al., 2011; Aggarwal et al., 2013; Shyamala et al., 2012), as there is higher prevalence of children with upper respiratory tract infections. In present study males $(60 \%)$ were affected more than females $(40 \%)$ which is in correlated to other studies (Aggarwal et al., 2013; Shyamala et al., 2012). Prevalence of CSOM was seen in rural areas $(81.9 \%)$ than compared to the urban areas (18.1\%). Aggarwal et al., (2013) (56\%) and Shaymala et al., (2012) (73\%), also showed the predominance of maximum number of cases from rural areas because of their low socioeconomic status, poor personal hygiene and lack of education.

In this study it was observed that the incidence of CSOM was mainly seen during the month of July- September (45.7\%). This is correlated with other studies like Wakode et al., (2006) with maximum number of cases seen during the month of July to October and Maji et al., which showed that maximum number of cases was seen during the months of May- October.

Out of 105 patients, 88 were positive for aerobic bacteria culture and remaining 17 were with no growth. Out of these 88 isolates, 83 were monobacterial and 5 were with polybacterial growth (83/5), which correlated with the study of Sharma et al., (2010) (70/10), Kshitiz et al., (2004) (147/26).

The present study Pseudomonas aeruginosa $33(31.4 \%)$ was the predominant organism followed by Staphylococcus aureus 28(26.6\%), Proteus mirabilis 9(5.7\%), Klebsiella pneumonia $7(4.7 \%)$, 
Streptococcus pneumonia 4(3.8\%), Acinetobacter 2(1.9\%) respectively.

Pseudomonas aeruginosa 33(31.4\%)was the most prominent isolate which correlated with other studies done by Arvind et al., (2014), Hirapure et al., (2014), Madana et al., (2011) and Sinha et al., (1999), whereas Prakash et al., (2013) and Srivastava et al., (2013) showed Pseudomonas aeruginosa as the second most commonest organism causing CSOM.

Second most predominant organism in the present study was Staphylococcus aureus 28(26.6\%) which correlated with the studies of Arvind et al., (2014), Hirapure et al., (2014), Madana et al., (2011) and Sinha et al. Staphylococcus aureus was the first predominant organism in studies done by Prakash et al., (2013) and Srivastava et al., (2010).

In the present study out 28 Staphylococcus aureus isolates, $10(35.7 \%)$ were MRSA producers and remaining 18(64.2\%) were MSSA producers. The present study correlates with the study of Biapasa Chakraborty et al., (2013) with 11(34.4\%), Raghvendera Singh Gaur et al., (2013) with 8(17.4\%) and Bansal Sulabh et al., (2013) with $10(27.8 \%)$ of MRSA producers.

In the present study among 18 Gram negative isolates, 5(27.7\%) were ESBL producers which correlated with the study of Bipasa Chakraborty et al., (2014) having 8(28.6\%) ESBL producers.

In the present study Vancomycin (100\%) was the most sensitive antibiotic of all which was correlated with the study of Arvind et al., (2014), Srivastava et al., (2010) and Bipasa Chakraborty et al., (2014). Amikacin was the second most sensitive antibiotic to many Gram positive isolates accounting for $81.2 \%$ which is correlated with the study of Arvind et al.,
(2013) and Bansal et al., (2013). In the present study Imipenem (94.4\%) was the most sensitive drug among the Pseudomoas aeruginosa isolates which correlates with the study of Arvind et al., (2013) and Aggarwal et al., Also Ceftriaxone is the second most sensitive drug in the present study which is in correlation with the work done by Aggarwal et al., Other antibiotics like Amikacin, Ceftazidime, Pipercillin and Tazobactum were also sensitive Pseudomonas which was correlated with the study of Bipasa Chakraborty et al., Bansal et $a l$. In the present study Imipenem was the most sensitive drug for the gram negative isolates accounting for $86.1 \%$ which was correlating with the study of Arvind et al., and Bipasa Chakraborty et al., (2014).

In conclusion, the present study highlights the bacterial profile of clinically diagnosed cases of CSOM, wherein polybacterial and monobacterial infections were isolated. Pseudomonas aeruginosa was the predomnaint organism which was isolated. Amikacin was the most sensitive drug amongst all the isolates. Since there are regional variations in aetiological agents and their antimicrobial susceptibility patterns, it is pertinent to carry out prospective studies to observe the profile of aetiological agents and their resistance patterns in order to prescribe appropriate and effective antibiotics and prevent emergence of multi drug resistant (MDR) bacteria.

\section{References}

Aggarwal, A., Kumar, D., Goyal, A. et al. 2013. Microbiological profile and their antimicrobial sensitivity pattern in patients of otitis media with ear discharge. Ind. J. Otol., 19(1): 5-8.

Arvind, N., Chand, P., Vishrutha, K.V. 2014. Microbiological profile of 
chronic suppurative otitis media. Int. J. Biomed. Res., 5(3): 204-6.

Bansal, S., Ojha, T., Kumar, S., et al. 2013. Changing microbiological trends in cases of chronic suppurative otitis media patients. Int. J. Cur. Res. Rev., 5(15): 76-81.

Chakraborty, B., Subhadip, D., Debashish, G., et al. 2014. Changing trends of antibiogram profile in patients with community acquired chronic otitis media in a tertiary care hospital. $J$. Evol. Med. Dent. Sci., 3(45): 11000-5.

Charles, M. 2006. Cummings. Textbook of Otolaryngology, 2nd Edition, chapter 157; Mosby year book, USA: 282339.

Dhingra, P.L. 2004. Dieases of ear, nose and throat; 3rd edition, chapter-4, Elsiever; 87-111.

Forber, B.A., Sahm, D.F., Weissfield. 1998. diagnostic microbiology. In: Bailey and Scott's, Missouri, Mosby Elsevier, $13^{\text {th }}$ edn: $238-42$.

Hirapure, P.V., Pote, M.K. 2014. Microbial profile and antibiogram of active patients of chronic suppurative otitis media in latur, Maharashtra, India. Int. Res. J. Med. Sci., 2(5): 6-9.

Kshtiz, B., Pannalal, Gupta, N. 2004. A study of clinico-microbiological profile of otitis media in rural Delhi. $J$. Antiseptic, 101(4): 142-4.

Madana, J., Yolmo, D., Kalaiarasi, R., et al. 2011. Microbiological profile with antibiotic sensitivity pattern of cholesteaomatous chronic suppurative otitis media among children. Int. J. Pediatr. Otorhinolaryngol., 75(9): 1104-8.

Maji, P.K., Chaterjee, T.K., Chaterjee, S., et al. 2007. The investigation of bacteriology of chronic suppurative otitis media in patients attending a tertiary care hospital with special emphasis on seasonal variation. Ind. J.
Otolaryngol. Head Neck Surg., 59(2): 128-31.

Miles, R.S., Amyes, S.G.B. 2007. Laboratory control of antimicrobial therapy. In: Gerald Colle J, Barrie P, Andrew GF, Anthony S, editors; New Delhi, Mackie and McCartney Practical medical microbiology, $2007 ; 14^{\text {th }}$ edn: $151-78$.

Mohammed, R., Mahmood, Y,. Ali, F. 2006. Comparison of different laboratory methods for detection of methicillin resistant staphylococcus aureus. Pak. J. Med. Sci., 22(4): 442-45.

Poorey, V.K., Iyer, A. 2002. Study of bacterial flora in CSOM and its clinical significance. Indian $J$. Otolaryngol. Head Neck Surg., 54(2): 91-5.

Prakash, M., Lakshmi, K., Anuradha, S., et al. 2013. Bacteriological profile and their antibiotic susceptibility pattern of cases of chronic suppurative otitis media. Asian J. Pharma. Clin. Res., 6(3): 210-11.

Raghvendra, S.G., Mathew, J., Mathew, V.A., et al. 2013. Microbiological pattern of ear swabs in chronically discharging ears in a tertiary care hospital in India. Indian J. Otol., 19(2): 51-4.

Sharma, K., Aggarwal, A., Khurana, P.M.S. 2010. Comparison of bacteriology in bilateral discharging ear in chronic suppurative otitis media, Ind. $J$. Otolayngol. Head Neck Surg., 62(2): 153-57.

Shyamala, R., Reddy, P., Sreenivasulu. 2012. The study of bacteriological agents of chronic suppurative otitis media-aerobic culture and evaluation. J. Microbiol. Biotechnol. Res., 2(1): 152-62.

Sinha, A., Kapil, A., Gupta, V. 1999. Aerobic bacteriological study of 
chronic suppurative otitis media. Ind. J. Otol., 5(4): 203-6.

Srivastava, A., Singh, R.K., Varshney, S., et al. 2010. Microbiological evaluation of an active tubotympanic type of chronic suppurative otitis media. Nepalese J. ENT Head and Neck Surgery, 1(2): 14-6.

Wakode, P.T., Joshi, S.V., Garwale, S.H. 2006. Chronic suppurative otitis media in school going children. Ind. $J$.
Otolaryngol. Head and Neck Surg., 58(2): 152-5.

Wariso, B.A., Ibe, S.N. 2006. Bacteriology of chronic discharging ears in port harcourt, Nigeria. West Afr. J. Med., 25(3): 219-22.

Washington, C.W., Stephen, D.A., William, M., et al. 2006. In:koneman's colour atlas and textbook of microbiology. Philadelphia; Lippincott's williams and walkins, 6th edn: 68-74.

\section{How to cite this article:}

Upasana Bhumbla, Shobha Paul, Dinesh Raj Mathur and Gyaneshwari. 2016. Bacterial Study of CSOM and their Changing Patterns of Antibiotic Sensitivity and Resistance. Int.J.Curr.Microbiol.App.Sci. 5(10): 282-288. doi: http://dx.doi.org/10.20546/ijcmas.2016.510.031 